\title{
Herbivore species identity mediates interspecific competition between plants
}

\author{
S. Ibanez ${ }^{1,3}$, M. Bison ${ }^{2}$, S. Lavorel ${ }^{2}$ and M. Moretti ${ }^{1}$ \\ ${ }^{1}$ Swiss Federal Research Institute WSL, Community Ecology Research Unit, CH-6500 Bellinzona, Switzerland \\ ${ }^{2}$ Laboratoire d'Ecologie Alpine UMR CNRS 5553 Université Joseph Fourier B.P.53, 38041 Grenoble, France \\ ${ }^{3}$ Corresponding author.Email: sebastien.ibanez@wsl.ch
}

Key words: Diet, Gomphocerinae, Grasshoppers, Plant competition, Tolerance.

\begin{abstract}
Herbivory is a major driver of plant communities. Most herbivores preferentially consume dominant species and slow down plant succession, but it remains unclear in which ways different herbivore species have contrasting effects on plant communities. In this study, we investigated the extent to which closely related insect herbivores with slight differences in their feeding behaviour induce contrasting reactions in plant communities. We studied the impact of herbivory by two Gomphocerinae grasshopper species, Chorthippus scalaris and Euthystira brachyptera, on the outcome of competition between the plant species Dactylis glomerata and Festuca paniculata. Under a controlled choice experiment, $C$. scalaris preferentially consumed D. glomerata while E. brachyptera preferred F. paniculata, but in an experimental plant community (mesocosm) both species consumed the plant species proportionally to their abundance and the amount of herbivory marks detected on the leaves did not depend on the specific grasshopper species. The herbivory pressure of both grasshopper species significantly reduced the vegetative height and the number of tillers of $F$. paniculata, with $C$. scalaris showing a stronger effect. As a consequence, herbivory by $E$. brachyptera did not significantly affect interspecific plant competition, whereas $C$. scalaris enhanced the dominance of $D$. glomerata. Our study shows that closely related herbivores that only slightly differ in their feeding behaviour can induce contrasting effects on interspecific plant competition, and that the dominant species D. glomerata is more tolerant to herbivory than $F$. paniculata. The specific plant and herbivore traits responsible for contrasting herbivory effects on plant competition remains to be explored.
\end{abstract}

Nomenclature: Fournier (2001) for higher plants and Baur et al. (2006) for grasshoppers.

\section{Introduction}

Herbivory is a major driver of the changes in the composition of plant communities (Hulme 1996, Schmitz et al. 2006, Olff and Ritchie 1998). Herbivores can mediate plant interspecific competition through their feeding preferences, which depend both on plant abundance (Ogden 1976, Speiser and Rowell-Rahier 1991, Singer and Stireman 2001) and plant traits (Pérez-Harguindeguy et al. 2003, Schädler et al. 2007, Ibanez et al. 2013). For example, when herbivores preferentially consume dominant plant species, they alter their competitive ability (Carson and Root 1999, Schädler et al. 2004), leading to an increase in plant diversity (Dyer et al. 2010). Even when herbivores are unselective, they can mediate plant interspecific competition through the differential susceptibility of plant species to grazing (Del-Val and Crawley 2005, Fornoni 2011). Consequently, herbivory-tolerant plant species will outcompete those that are intolerant, and how well plants tolerate herbivory will determine their competitive ability within the community. Therefore, when herbivores exert significant pressure, e.g., in terms of biomass removal, we expect dominant plant species to be more tolerant to herbivory.

Herbivores have very diverse feeding preferences (Negi et al. 1993, Joern 1983) and in the case of insects, they eat plant tissues in a variety of ways, which in turn implies that herbivore identity can be a mediator of plant diversity because of the differential effects on plant competition. Related mammalian species can have contrasting effects on plant communities (Loucougaray et al. 2004, Jáuregui et al. 2009), but few studies have explored whether this is also the case for insects. In a recent exclusion experiment, Allan and Crawley (2011) showed that insect and molluscan herbivores had contrasting long-term effects within natural plant communities. Molluscs and insects are very distant taxa and have contrasting locations within the vegetation, where molluses mainly consumed forb seedlings whereas insects preferred grasses. Whether closely related herbivores with similar behaviours, body sizes and locations in the vegetation can have contrasting impact on plant communities is however not known. We hypothesize that closely related herbivores can induce contrasting effects in plant communities, due to differences in their diet. This question is of particular importance in a community ecology context, where different communities of herbivores might have contrasting effects on the dynamics of plant communities (Olff and Ritchie 1998, Ravolainen et al. 2011, Allan and Crawley 2011).

To test this hypothesis, we studied the impact of herbivory by two Gomphocerinae grasshopper species, Chorthippus scalaris and Euthystira brachyptera, on interspecific 
plant competition in an experimental plant community consisting of the faster-growing and nitrogen-richer Dactylis glomerata, and the slower-growing and nitrogen-poorer Festuca paniculata. Based on previous experiments (Gross et al. 2007b), we expected that in the absence of grasshoppers, the faster-growing $D$. glomerata would outcompete the slowergrowing $F$. paniculata. In the presence of grasshoppers, two opposing mechanisms were expected. First, grasshoppers would prefer to feed on the nitrogen-richer D. glomerata (Heidorn and Joern 1987, Pérez-Harguindeguy et al. 2003), thereby decreasing its competitive ability (Carson and Root 1999, Schädler et al. 2004). Second, being faster-growing, $D$. glomerata would be more tolerant to herbivory than F. paniculata (Zou et al. 2008, Fornoni 2011), which would increase its competitive ability. We finally expected that the balance between these two mechanisms would depend on the feeding patterns of the two grasshopper species. In other words, given significantly different feeding patterns, the competition between the plant species would depend on the identity of the grasshopper species. More specifically, since C. scalaris prefers softer plants than E. brachyptera, and D. glomerata is softer than F. paniculata (Ibanez et al. 2013), we expected that $C$. scalaris would consume D. glomerata in greater amounts than E. brachyptera, so that the competitive ability of $D$. glomerata would be reduced in the presence of C. scalaris.

\section{Material and methods}

\section{Study area, plant and insect species}

The experiments were conducted at the Station Alpine Joseph Fourier, at the Lautaret pass $(2100 \mathrm{~m})$ in the central French Alps. All plants and individuals were collected in the neighbouring subalpine grasslands, on the south-facing aspect of the commune of Villard d'Arène, ranging from 1700 to $2100 \mathrm{~m}$ (Quétier et al. 2007).

As model plants, we used two dominant perennial tussock species, the conservative Festuca paniculata which has a slow growth, tough leaves and high $\mathrm{C} / \mathrm{N}$, and the exploitative Dactylis glomerata, which has tender leaves, fast growth and low C/N (Gross et al. 2007a).

As model herbivores, we used two Gomphocerinae grasshoppers, the habitat generalist Chorthippus (Stauroderus) scalaris which is present in most plant communities in the study area, and the habitat specialist Euthystira brachyptera which is restricted to tall-grass meadows and shaded environments (Baur et al. 2006).

Choice experiment. In June 2010, grasshopper larvae collected in the field were first gathered in mesocosms covered by a nylon mesh containing $F$. paniculata and $D$. glomerata in equal proportions, in order to standardise their feeding learning history prior to the experiment. Once adults, 24 individual grasshoppers (6 females and 6 males of each species) were starved for one night and introduced separately into a $40 \mathrm{~cm} \times$ $20 \mathrm{~cm} \times 4 \mathrm{~cm}$ box in which they could choose between one $F$. paniculata and one D. glomerata leaf that were kept hy- drated before and during the experiment. Five hours later, the individual grasshopper was removed and we checked whether it had eaten one of the species, or both, or neither.

Mesocosm experiment. In early May 2010, single tillers of both species were separated from large tussocks and planted in individual $9 \times 9 \times 10 \mathrm{~cm}$ containers filled with potting soil. One month later, 24 individual plants were planted in large pots (mesocosms: $\varnothing 45 \mathrm{~cm}$, height $50 \mathrm{~cm}$ ) filled with a standard mixture of sand (2/3), vermiculite (1/6) and potting soil $(1 / 6)$, according to the following design:

1. "D" treatment: 21 D. glomerata and $3 F$. paniculata individuals (i.e., 7:1)

2. "F" treatment: 3 D. glomerata and $21 F$. paniculata individuals (i.e., 1:7).

3. " 50 " treatment: $12 \mathrm{D}$. glomerata and $12 \mathrm{~F}$. paniculata individuals (i.e., 1:1).

One month later, the pots were covered with nylon mesh and 4 adult grasshoppers were introduced as follows:

1. "Cs" treatment: 2 males and 2 females of Chorthippus scalaris.

2. "Eb" treatment: 2 males and 2 females of Euthystira brachyptera.

3. "CsEb" treatment: 1 male and 1 female of each species.

4. "0" treatment: no grasshoppers.

Each of the twelve treatment combinations $(3 \times 4)$ was replicated 4 times, giving 48 mesocosms in total. The mesocosms were checked once a week and dead grasshopper bodies were removed and replaced by living ones, in order to keep the herbivory pressure constant. New introduced grasshopper individuals were exposed to both plant species for at least seven days to standardise their feeding learning history prior to the experiment. The overall mesocosm experiment lasted from June 29 until September 27, 2010. From the 19 to the 23 of July 2010, we defined a "herbivory index" to measure the impact of herbivory on the 12 individual plants of each mesocosm that were located in the centre of the pots. To do this, we recorded all visible bites on the leaves of each plant and the size of the individual bites were estimated on a 1-7 integer scale. For each individual plant, the herbivory index corresponded to the sum of bites. On the 27th of September, the vegetative plant height was measured and the number of tillers counted for all individuals. Based on the assumption that the biomass of the tillers is proportional to their height, the biomass was estimated by multiplying the plant height by the number of tillers and taking the sum for all the individuals of each species. We defined the proportion of $D$. glomerata tillers in each mesocosm as the number of $D$. glomerata tillers divided by the total number of tillers in each mesocosm. The proportion of the herbivory index of $D$. glomerata and the proportion of biomass of $D$. glomerata were calculated in the same manner.

Grasshoppers' diet. From 19 to 23 July, during the measurement of the herbivory index, grasshopper individuals were 
removed from the mesocosms and put in single tubes from which we collected the faeces to estimate the proportion of consumed tissue of each plant species. Immediately after the faeces collection, the grasshoppers were put back in the mesocosms. Out of the 144 individuals that were collected in this way, 73 individuals ( 38 C. scalaris, 35 E. brachyptera) produced faeces in their tube. Each collected amount of faeces was crushed in $60 \%$ ethanol to prevent bacterial development, prepared between cover glass and slide glass, and stabilized with varnish. The slide glasses were observed with a light microscope (TV Lens C-0,6x, Nikon Japan, Eclipse E$600)$. D. glomerata and $F$. paniculata fragments can be distinguished based on their cell walls, with $F$. paniculata being milled and $D$. glomerata straight. First, 8 randomly chosen slides were photographed and the area of each plant fragment estimated with the free software JMicroVision (Roduit 2013). Area classes ranging from 0.1 to $0.5 \mathrm{~mm}^{2}$ with a 0.1 $\mathrm{mm}^{2}$ increment were defined based on these measurements. Then, all 73 slides were observed and each plant fragment identified as either D. glomerata or $F$. paniculata. These were then assigned to a size class without direct measurement, except for the fragments larger than $0.5 \mathrm{~mm}^{2}$ which were measured with JMicroVision. Finally, for each slide, the total area of the fragments belonging to D. glomerata and $F$. paniculata, and the proportion of D. glomerata in the total area were calculated.

\section{Statistical analysis}

Choice experiment. We estimated the effect of plant species, grasshopper species, and sex on consumption probability using a binomial generalised linear mixed model with the function lmer of the lme4 package (Bates et al. 2011) including the plant species, grasshopper species and sex as fixed effects and the individuals as random effects. Sex was included in the analysis because females might have different feeding preferences compared to males due to their reproductive status. 14 different models, ranging from the complete model (that includes all interaction terms among the three factors) to an intercept model were calculated. The models were then compared based on their Akaike Information Criterion (AIC), and we selected the model with the lowest AIC. The pairwise differences among treatments were tested with the Tukey test, using the "glht" function of the "multcomp" package (Hothorn et al. 2008), that includes correction for multiple testing. Confidence intervals of the consumption probabilities were estimated using the "confint" function.

Grasshoppers' diet in the mesocosms. We estimated the effects of grasshopper species and of the proportion of $D$. glomerata tillers in the mesocosms on the proportion of $D$. glomerata fragments in the faeces using a gaussian linear mixed model that included the grasshopper species and plant composition as fixed effects and the mesocosms as random effects. This was followed by a type II Anova using the car package (Fox and Weisberg 2011). Because the proportion of D. glomerata tillers in the mesocosms was measured in September 2010 whereas the faeces were collected in July 2010 , we assumed that the plant community change throughout the experiment was steady and occurred at a similar rate across all mesocosms. We used the final proportion of $D$. glomerata tillers instead of the initial proportion of the plant species since, by July, the mesocosms were already closer to their final than to their initial composition.

Plant height and number of tillers. The effects of herbivory on the plant communities in the mesocosms (plant height, number of tillers and herbivory index) were assessed using a gaussian linear mixed model that included the grasshopper and plant treatments as fixed effects and the mesocosms as random effects. The significance of pairwise differences between treatments was tested with Tukey tests using the "glht" function (Hothorn et al. 2008). The herbivory index was square-root transformed to achieve normality.

Interspecific plant competition. We estimated the effect of grasshopper and plant treatments on the proportion of $D$. glomerata tillers, biomass and herbivory index with gaussian linear models, and tested pairwise differences between treatments with Tukey tests using the "glht" function (Hothorn et al. 2008), after checking for normality. The heterogeneity of variances was taken into account using the "sandwich" package (Zeileis 2006). We used the free R software (R Development Core Team 2011) for all the analyses.

\section{Results}

\section{Choice experiment}

Our AIC-based model selection procedure showed that plant consumption probability differed between plant and herbivore species, but not between sexes (Appendix 1). F. paniculata had a higher consumption probability when ex-
Figure 1. Consumption probabilities of $D$. glomerata and $F$. paniculata by $C$. scalaris and E. brachyptera, assessed by the choice experiment. Measures that do not share any letter are significantly different. The brackets correspond to the $95 \%$ confidence intervals.

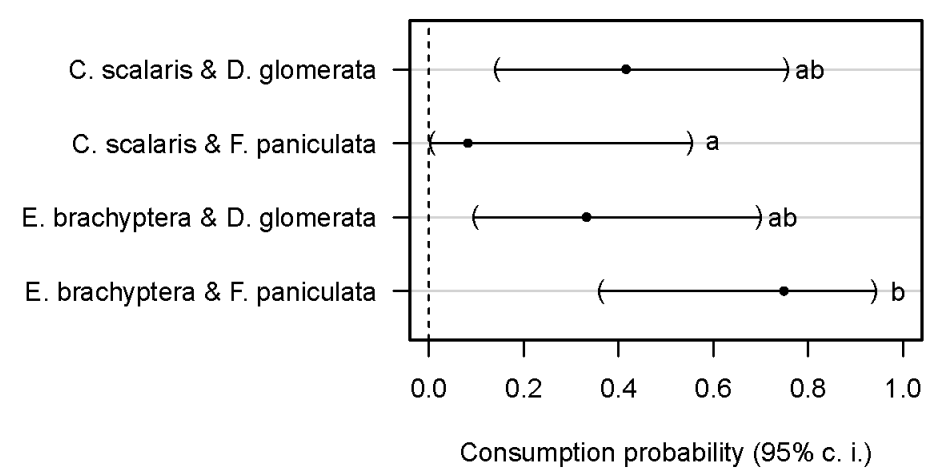


posed to E. brachyptera than when exposed to C. scalaris, while consumption probability of $D$. glomerata did not differ between herbivore species (Fig. 1).

\section{Grasshoppers' diet in the mesocosms.}

In the mesocosms, both grasshopper species consumed D. glomerata in similar proportions $\left(\chi_{1 \text { d.f. }}^{2}=0.28, \mathrm{p}=0.58\right)$. The proportion of $D$. glomerata in their diet was strongly linked to the proportion of $D$. glomerata tillers in the meso$\operatorname{cosms}\left(\chi_{1 \text { d.f. }}^{2}=60.31, p<10^{-14}\right.$, Fig. 2$)$, and the slope of this relationship was not affected by grasshopper species identity $\left(\chi_{1 \text { d.f. }}^{2}=0.39, \mathrm{p}=0.53\right)$.

The herbivory index gave similar results to the proportion of D. glomerata fragments in the faeces. Both estimates of D. glomerata consumption were correlated $\left(\mathrm{F}_{1,31}=33.06\right.$, $\mathrm{R}^{2}=0.50, \mathrm{p}<10^{-5}$ ), and the proportion of herbivory index measured on D. glomerata was correlated to the proportion of D. glomerata tillers in the mesocosms $\left(\mathrm{F}_{1,34}=23.59\right.$, $\left.\mathrm{R}^{2}=0.39, \mathrm{p}<10^{-4}\right)$.

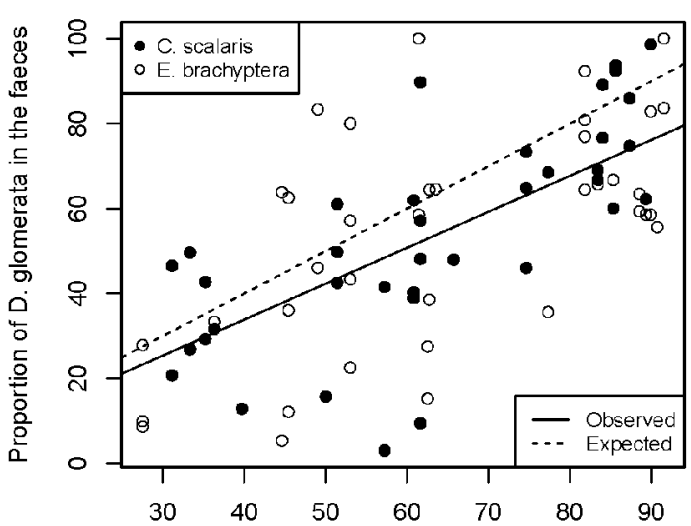

Proportion of D. glomerata tillers in the mesocosms
Figure 2. Proportion of D. glomerata fragments in the faeces explained by the proportion of $D$. glomerata tillers in the mesocosms. Black circles: C. scalaris, open circles: E. brachyptera. Bold line: observed relationship, dotted line: relationship expected if grasshoppers are not choosy $(y=1)$.
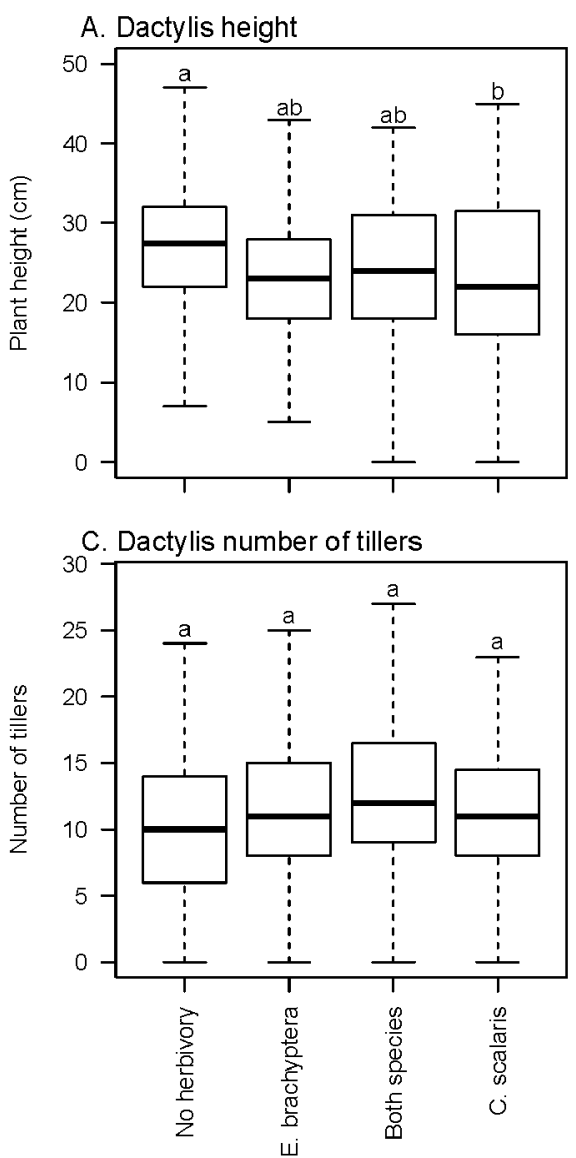

B. Festuca height

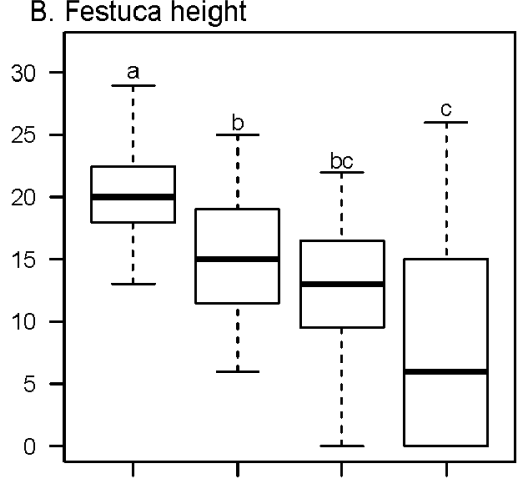

D. Festuca number of tillers

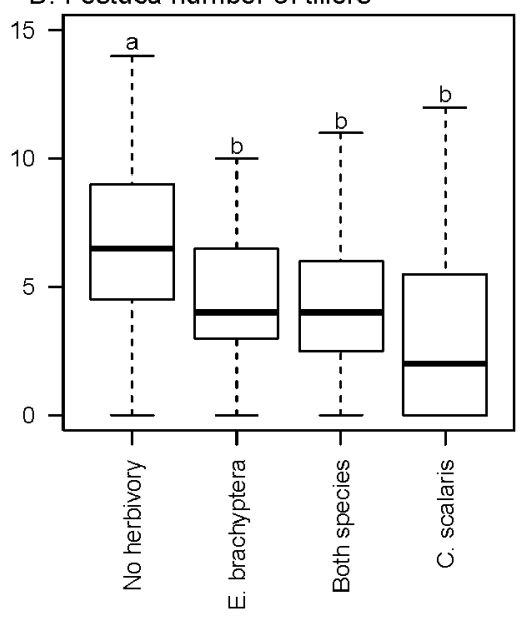

Figure 3. Plant height (A and $\mathrm{B})$ and number of tillers $(C$ and $D)$ of both plant species in function of the grasshopper treatment in the mesocoms. Each box represents the lower quartile, the median (bold line), and the upper quartile. The notches correspond roughly to a $95 \%$ confidence interval. The letters above each box correspond to the result of the Tukey test, boxes that do not share any letter are significantly different. 


\section{Plant height and number of tillers}

Herbivory did not affect the height of $D$. glomerata, except when C. scalaris was the only species present (Fig. 3A). Instead, herbivory decreased the height of $F$. paniculata in
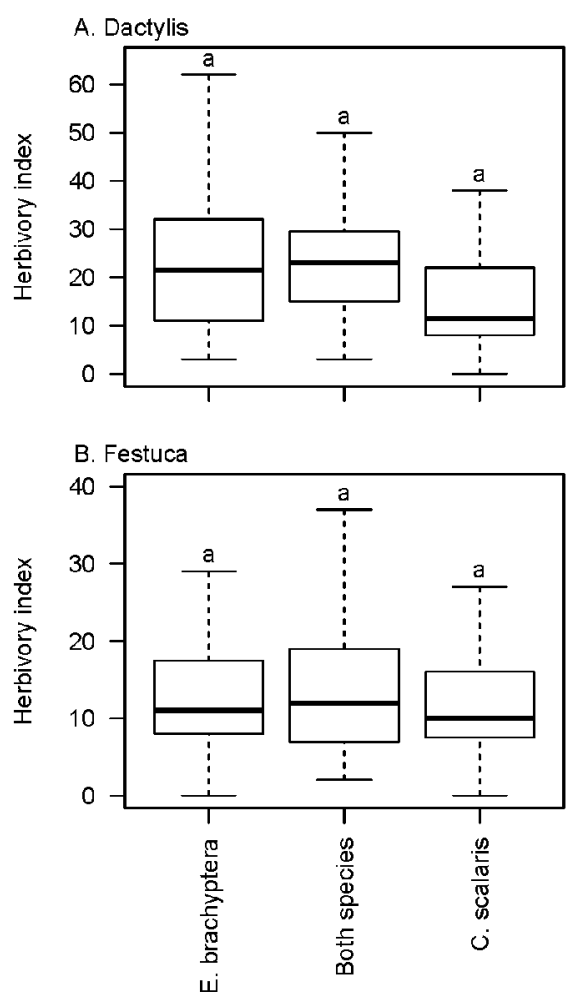

Figure 4. Herbivory index of D. glomerata (A) and F. paniculata (B) in function of the grasshopper species present in the mesocosms. Each box represents the lower quartile, the median (bold line), and the upper quartile. The notches correspond roughly to a $95 \%$ confidence interval. The letters above each box correspond to the result of the Tukey test, boxes that do not share any letter are significantly different. all grasshopper treatments (Fig. 3B). Herbivory did not affect the number of tillers of D. glomerata (Fig. 3C), and it reduced the number of tillers of $F$. paniculata (Fig. 3D). The herbivory index measured either on D. glomerata or on $F$. paniculata was independent of the grasshopper species (Fig. 4). Herbivory did not affect the proportion of D. glomerata tillers in the mesocosms, except when C. scalaris was present alone (Fig. 5A). The same pattern was observed for the proportion of D. glomerata biomass (Fig. 5B). The effects of herbivory on plant traits did not depend on the initial plant composition of the mesocosms (details not shown, $p>0.05$ in all cases), except when herbivory by $C$. scalaris decreased the number of $D$. glomerata tillers when $F$. paniculata was initially more abundant ("F" plant treatment, $\chi^{2} 6$ d.f. $=13.11$, $\mathrm{p}=0.04)$.

\section{Interspecific plant competition}

In order to compare the effects of herbivory on both plant species, we now focus on its effects on the proportion of $D$. glomerata tillers, biomass and herbivory index, relative to $F$. paniculata. Herbivory by C. scalaris, but not by E. brachyptera, increased the proportion of D. glomerata tillers (Fig. 5A) and biomass (Fig. 5B) in the mesocosms. An intermediate but not significant pattern was observed when both grasshopper species were present. The proportion of herbivory index recorded on D. glomerata did not depend on the grasshopper species present (Fig 5C). The effects of herbivory on interspecific plant competition did not depend on the initial plant composition of the mesocosms (details not shown, $\mathrm{p}>0.05$ in all cases),

\section{Discussion}

Numerous investigations have demonstrated that herbivory interacts antagonistically with plant competition (Haag et al. 2004, Schädler et al. 2007, Boege 2010). When herbivores preferentially consume the dominant species, they can inverse plant competition and favour subordinate
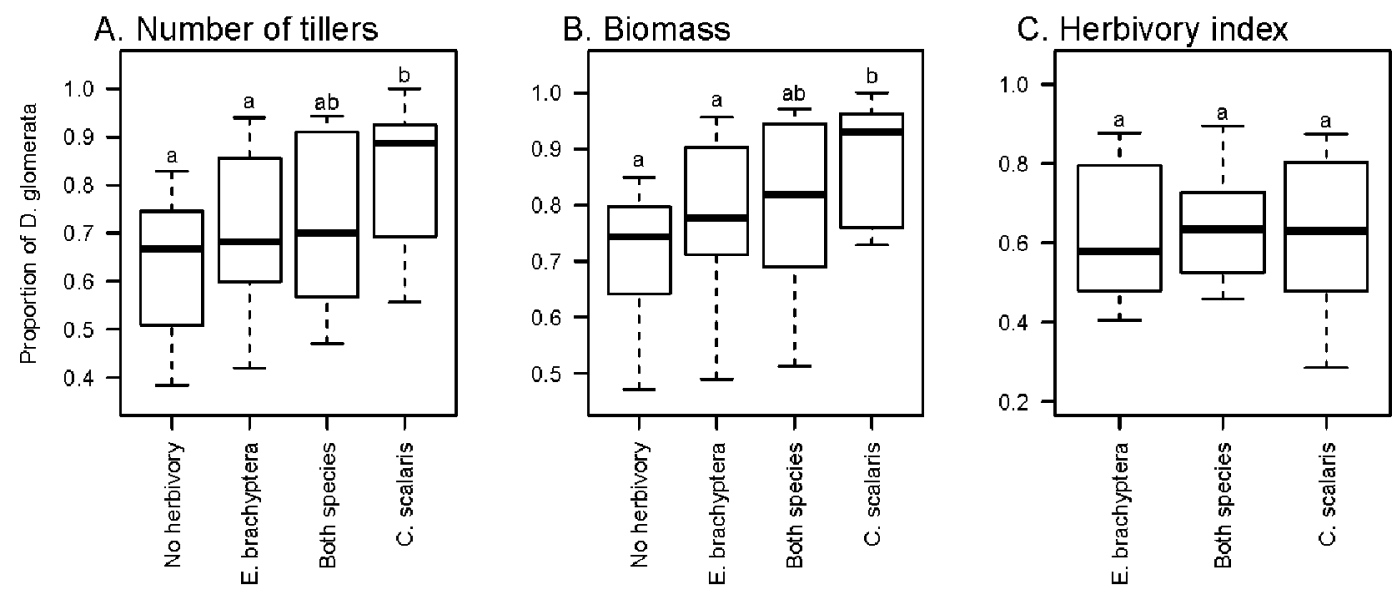

Figure 5. Proportion of D. glomerata in the total amount of (A) tillers, (B) biomass and (C) herbivory index in each mesocosm. Each box represents the lower quartile, the median (bold line), and the upper quartile. The notches correspond roughly to a $95 \%$ confidence interval. The letters above each box correspond to the result of the Tukey test, boxes that do not share any letter are significantly different. 
species (Carson and Root 1999). In our experiments, and contrary to our expectations, the two grasshopper species did not preferentially eat the faster-growing $D$. glomerata, which quickly became the most abundant plant species in the mesocosms, as was the case in previous experiments (Gross et al. 2007a). Instead, they consumed the two plant species proportionally to their abundance in the experimental communities (Fig. 2). As a consequence, herbivory did not reduce the competitive ability of $D$. glomerata, but instead favoured $D$. glomerata in its competition against $F$. paniculata (Fig. 5), exacerbating the effects of competition (Cipollini and Bergelson, 2002). This can be explained by its greater tolerance to herbivory, and more generally to disturbance (Gross et al. 2007a). Indeed, it has been shown that the slow-growing species $F$. paniculata is strongly affected by mowing (Baptist et al. 2013), and that faster growing species are more tolerant to herbivory (Jones et al. 2006, Zou et al. 2008). Tolerant species are therefore more likely to dominate plant communities, just as tolerant genotypes are more likely to spread in plant populations (Fornoni 2011). Consequently, we observed a synergistic interaction between herbivory and plant competition, rather than an antagonistic interaction (Haag et al. 2004, Schädler et al. 2007). Our results support the hypothesis that dominant species are more tolerant to herbivory.

However, herbivory by E. brachyptera did not significantly modify the proportion of D. glomerata (Fig. 5). Why these two herbivore species belonging to the same subfamily, both being grazers and having the same feeding pattern during the experiment (Fig. 2), had contrasting effects on plant competition is intriguing. One might argue that E. brachyptera, which is smaller than $C$. scalaris, consumed less plant matter than E. brachyptera, thereby having a statistically undetectable effect on plant competition. However, the herbivory index we used, which is related to the amount of plant eaten, did not show any significant effect caused by grasshopper identity (Fig. 4). A more likely explanation stands if both species consume different plant parts, in particular if $C$. scalaris tends to eat more younger leaves or buds than $E$. brachyptera. We have no data regarding the position, age or quality of the leaves of the same individual plants that were consumed by the two grasshopper species. However, during the choice experiment, C. scalaris did prefer the soft-leaved $D$. glomerata to the hard-leaved $F$. paniculata. We therefore hypothesise that in the mesocosms $C$. scalaris might have eaten tender and younger leaves than E. brachyptera, thereby hampering regrowth.

In conclusion, we have shown that closely related herbivore species, with slightly different feeding preferences in choice experiments, but similar diets in experimental communities, can have contrasting effects on plant succession. Because grasshoppers consume up to $30 \%$ of the plant biomass in alpine grasslands (Blumer and Diemer 1996) where our study took place, we believe that the effects reported here in mesocosms can also occur in the field. These results further suggest that the effect of a distinct community of herbivores on plant community composition is unpredictable given current knowledge. Moreover, while our ex- periment used adults, it is known that grasshoppers shift their diet throughout their ontogeny (e.g., Dopman et al. 2002), which adds unpredictability to the system. Differences in the community composition of related herbivores can lead to contrasting effects on plant communities. Our results suggest that our ability to predict how herbivores affect plant communities depends on detailed knowledge about their feeding preferences, but also on their feeding patterns with regards to single plant individuals, as well as on plant traits linked to their tolerance to herbivory. Other traits involved in the plant-herbivore relationship might also be at play, such as the induction of secondary compounds following herbivory. Such trait-based approaches will be required for a more mechanistic understanding of plant-herbivore interactions, and to predict the influence of herbivory on plant interspecific competition.

Acknowledgements: We are grateful to O. Manneville, S. Bec and Q. Duparc for their help with the experiments, to F. van der Plas and two anonymous reviewers for their helpful comments, and to C. Gautschi for his help with language. This research was conducted at the Station Alpine Joseph Fourier (UMS CNRS 3370, France) and on the long-term research site Zone Atelier Alpes (ZAA), a member of the ILTER-Europe network. ZAA publication no. 26.

\section{References}

Allan, E. and Crawley, M. J. 2011. Contrasting effects of insect and molluscan herbivores on plant diversity in a long-term field experiment. Ecol. Lett. 14: 1246-1253.

Baptist, F., Secher-Fromell, H., Viard-Cretat, F., Aranjuelo, I., Clement, J.-C., Creme, A., Desclos, M., Laine, P., Nogues, S. and Lavorel, S. 2013. Carbohydrate and nitrogen stores in Festuca paniculata under mowing explain dominance in subalpine grasslands. Plant Biol. in press.

Bates, D., Maechler, M. and Bolker, B. 2011. Ime4: Linear mixedeffects models using S4 classes. R package version 0.999375-39.

Baur, B., Baur, H., Roesti, C., Roesti, D. and Thorens, P. 2006. Sauterelles, Grillons et Criquets de Suisse. Haupt, Berne.

Blumer, P. and Diemer, M. 1996. The Occurrence and Consequences of Grasshopper Herbivory in an Alpine Grassland, Swiss Central Alps. Arctic Alpine Res. 28: 435-440.

Boege, K. 2010. Induced responses to competition and herbivory: natural selection on multi-trait phenotypic plasticity. Ecology 91: 2628-2637.

Carson, W. P. and Root, R. B. 1999. Top-down effects of insect herbivores during early succession: influence on biomass and plant dominance. Oecologia 121: 260-272.

Cipollini, D. F. and Bergelson, J. 2002. Interspecific competition affects growth and herbivore damage of Brassica napus in the field. Plant Ecol. 162: 227-231.

Del-Val, E. and Crawley, M. J. 2005. Are grazing increaser species better tolerators than decreasers? An experimental assessment of defoliation tolerance in eight British grassland species. $J$. Ecol. 93: 1005-1016.

Dopman, E. B., Sword, G. A. and Hillis, D. M. 2002. The importance of the ontogenetic niche in resource-associated divergence: evidence from a generalist grasshopper. Evolution 56: 731-740.

Dyer, L. A., Letourneau, D. K., Chavarria, G. V. and Amoretti, D. S. 2010. Herbivores on a dominant understory shrub increase local 
plant diversity in rain forest communities. Ecology 91: 37073718 .

Fornoni, J. 2011. Ecological and evolutionary implications of plant tolerance to herbivory. Funct. Ecol. 25: 399-407.

Fournier, P. 2001. Les Quatre Flores de France. Dunod, Paris.

Fox, J. and Weisberg, S. 2011. An R Companion to Applied Regression. Sage, Thousand Oaks, CA.

Gross, N., Suding, K. N. and Lavorel, S. 2007a. Leaf dry matter content and lateral spread predict response to land-use change for six subalpine grassland species. J. Veg. Sci. 18: 289-300.

Gross, N., Suding, K. N., Lavorel, S. and Roumet, C. 2007b. Complementarity as a mechanism of coexistence between functional groups of grasses. J. Ecol. 95: 1296-1305.

Haag, J. J., Coupe, M. D. and Cahill Jr, J. F. 2004. Antagonistic interactions between competition and insect herbivory on plant growth. J. Ecol. 92: 156-167.

Heidorn, T. J. and Joern, A. 1987. Feeding preference and spatial distribution of grasshoppers (Acrididae) in response to nitrogen fertilization of Calamovilfa longifolia. Funct. Ecol. 1: 369-375.

Hothorn, T., Bretz, F. and Westfall, P. 2008. Simultaneous inference in general parametric models. Biometrical J. 50: 346-363.

Hulme, P. E. 1996. Herbivory, plant regeneration, and species coexistence. J. Ecol. 84: 609-615.

Ibanez, S., Lavorel, S., Puijalon, S. and Moretti, M. 2013. Herbivory mediated by coupling between biomechanical traits of plants and grasshoppers. Funct. Ecol. in press.

Jáuregui, B. M., García, U., Osoro, K. and Celaya, R. 2009. Sheep and Goat Grazing Effects on Three Atlantic Heathland Types. Rangeland Ecol. Manage. 62: 119-126.

Joern, A. 1983. Hostplant utilization by grasshoppers (Orthoptera: Acrididae) from a Sandhills prairie. J. Range Manage. 36: 793797.

Jones, T., Kulseth, S., Mechtenberg, K., Jorgenson, C., Zehfus, M., Brown, P. and Siemens, D. 2006. Simultaneous evolution of competitiveness and defense: induced switching in Arabis drummondi. Plant Ecol. 184: 245-257.

Loucougaray, G., Bonis, A. and Bouzillé, J.-B. 2004. Effects of grazing by horses and/or cattle on the diversity of coastal grasslands in western France. Biol. Conserv. 116: 59-71.

Negi, G. C. S., Rikhari, H. C., Ram, J. and Singh, S. P. 1993. Foraging niche characteristics of horses, sheep and goats in an alpine meadow of the Indian Central Himalaya. J. Appl. Ecol. 30: 383394.

Ogden, J. 1976. Some aspects of herbivore-plant relationships on Caribbean reefs and seagrass beds. Aquatic Bot. 2: 103-116.

Olff, H. and Ritchie, M. E. 1998. Effects of herbivores on grassland plant diversity. Trends Ecol. Evol. 13: 261-265.

Pérez-Harguindeguy, N., Díaz, S., Vendramini, F., Cornelissen, J. H. C., Gurvich, D. E. and Cabido, M. 2003. Leaf traits and herbivore selection in the field and in cafeteria experiments. Austral Ecol. 28: 642-650.
Quétier, F., Thébault, A. and Lavorel, S. 2007. Linking vegetation and ecosystem response to complex past and present land use changes using plant traits and a multiple stable state framework. Ecol. Monogr. 77: 33-52.

R Development Core Team 2013. R: A language and environment for statistical computing. R Foundation for Statistical Computing, Vienna, Austria. ISBN 3-900051-07-0, URL http://www.R-project.org/ (accessed 22 April 2013).

Ravolainen, V. T., Bråthen, K. A., Ims, R. A., Yoccoz, N. G., Henden, J.-A. and Killengreen, S. T. 2011. Rapid, landscape scale responses in riparian tundra vegetation to exclusion of small and large mammalian herbivores. Basic Appl. Ecol. 12: 643-653.

Roduit, N. 2013. JmicroVision, Image analysis toolbox for measuring and quantifying components of high-definition images. Version 1.2.2. http://www.jmicrovision.com (accessed 22 April 2013).

Schädler, M., Brandl, R. and Haase, J. 2007. Antagonistic interactions between plant competition and insect herbivory. Ecology 88: $1490-8$.

Schädler, M., Jung, G., Brandl, R. and Auge, H. 2004. Secondary succession is influenced by belowground insect herbivory on a productive site. Oecologia 138: 242-252.

Schmitz, O., Kalies, E. and Booth, M. 2006. Alternative dynamic regimes and trophic control of plant succession. Ecosystems 9: 659-672.

Singer, M. and Stireman, J. 2001. How foraging tactics determine host-plant use by a polyphagous caterpillar. Oecologia 129: 98105.

Speiser, B. and Rowell-Rahier, M. 1991. Effects of food availability, nutritional value, and alkaloids on food choice in the generalist herbivore Arianta arbustorum (Gastropoda: Helicidae). Oikos 62: 306-318.

Zeileis, A. 2006. Object-oriented computation of sandwich estimators. J. Stat. Software 16: 1-16.

Zou, J., Rogers, W. and Siemann, E. 2008. Increased competitive ability and herbivory tolerance in the invasive plant Sapium sebiferum. Biol. Invasions 10: 291-302.

Received August 27, 2012
Revised January 11, 2013
Accepted February 5, 2013

\section{Appendix 1}

Number of parameters, Akaike Information Criterion (AIC), Bayesian Information Criterion (BIC) and log-likelihood of the 14 models calculated to analyse the plant preferences by grasshoppers in controlled conditions. The file may be downloaded from the web site of the publisher at www.akademiai.com. 